\title{
PENGELOLAAN SAMPAH MANDIRI BERBASIS MASYARAKAT DI KELURAHAN RANGKAPAN JAYA BARU KECAMATAN PANCORAN MAS KOTA DEPOK SEBAGAI UPAYA PENINGKATAN EKONOMI MASYARAKAT
}

\author{
Sri Sulasminingsih ${ }^{1}$, Noegrahini $\mathbf{L}^{2}$, dan Marlina $^{3}$ \\ ${ }^{1}$ Program Studi Teknik Industri, Fakultas Teknik UPN "Veteran" Jakarta \\ ${ }^{2}$ Program Studi D3 Akuntansi, Fakultas Ekonomi dan Bisnis UPN "Veteran" Jakarta \\ ${ }^{3}$ Program Studi S1 Manajemen, Fakultas Ekonomi dan Bisnis UPN "Veteran" Jakarta
}

\begin{abstract}
Household waste in the form of organic and non-organic materials can be utilized as material with economic value. Community Engagement Program is carried out in RW. 03 Kelurahan Rangkap Jaya Baru, Depok City aims to (1) increase public awareness of the importance of managing and managing waste independently, (2) increasing community knowledge and insight that waste processing units do not cause air pollution, sources of disease, and discomfort, (3) increase community knowledge and insights on various techniques for making compost independently, and (4) providing training to the community on processing waste into compost that has economic value. As an effort to manage solid waste, this is to reduce the problem of garbage, recycling of waste, the use of waste as organic fertilizer. The method used is to provide training on waste management and its application in daily life. Organic material can be used as compost by using integrated waste treatment technology, which is carried out in a practical, clean, and odorless form so that it is very safe to use for household scale. While non-organic materials can be directly utilized as materials that can be recycled. The output targets of the PKM program are (1) the community has begun to realize the importance of independent waste management and processing, (2) the community has the knowledge and ability of processing waste into goods that have economic value, and (3) the creation of active community participation in solving the problem of waste by providing temporary shelter at the family, RT and RW levels, so as to create an environment that is clean, comfortable and free from garbage pollution.
\end{abstract}

Keywords: waste sorting; non-organic waste; organic matter; compost.

\section{ABSTRAK}

Sampah rumah tangga berupa bahan organik dan non-organik dapat dimanfaatkan menjadi bahan yang bernilai ekonomis. Program Pengabdian kepada Masyarakat (PKM) ini dilaksanakan di RW. 03 Kelurahan Rangkapan Jaya Baru Kota Depok bertujuan untuk (1) meningkatkan kesadaran masyarakat pentingnya pengelolaan dan pengolahan sampah secara mandiri, (2) meningkatkan pengetahuan dan wawasan masyarakat bahwa unit pengolah sampah tidak menyebabkan polusi udara, sumber penyakit, dan ketidaknyamanan, (3) meningkatkan pengetahuan dan wawasan masyarakat tentang berbagai teknik pembuatan kompos secara mandiri, dan (4) memberikan pelatihan kepada masyarakat tentang pengolahan sampah menjadi kompos yang memiliki nilai ekonomis. Sebagai upaya pengelolaan sampah ini adalah untuk mengurangi permasalahan sampah, daur ulang sampah, pemanfaatan sampah sebagai pupuk organic.. Metode yang digunakan adalah dengan memberikan pelatihan tentang pengelolaan sampah dan penerapannya dalam kehidupan sehari-hari. Bahan organik dapat dimanfaatkan sebagai pupuk kompos dengan menggunakan teknologi pengolahan sampah terpadu, pengolahan sampah yang dilakukan bentuknya praktis, bersih, dan tidak berbau sehingga sangat aman digunakan untuk skala rumah tangga. Sedangkan bahan non-organik dapat langsung dimanfaatkan sebagai bahan yang dapat didaur ulang. Target luaran program PKM ini adalah (1) masyarakat mulai menyadari akan pentingnya pengelolaan dan pengolahan sampah secara mandiri, (2) masyarakat memiliki pengetahuan dan kemampuan tentang teknik pengolahan sampah menjadi barang yang memiliki nilai ekonomis, dan (3) terciptanya peran serta masyarakat secara aktif dalam memecahkan masalah sampah dengan menyediakan tempat penampungan sampah sementara baik ditingkat keluarga, $R T$ dan RW, sehingga tercipta suatu lingkungan yang bersih, nyaman dan terbebas dari pencemaran sampah.

Kata kunci: pilah sampah; sampah non organik; bahan organik; kompos.

\section{PENDAHULUAN}

Di era globalisasi ini persoalan lingkungan menjadi isu global (mendunia), setelah hampir semua elemen masyarakat menyadari akan bahaya yang ditimbulkan dari kerusakan lingkungan, hal ini berpengaruh terhadap terjadinya perubahan iklim, timbulnya bencana, timbulnya pandemi 
penyakit, serta kelangsungan hidup manusia, binatang, dan tumbuhan beserta spesies-spesies lainnya. Sampah merupakan sebagian dari sesuatu yang tidak dipakai, tidak disenangi atau sesuatu yang harus dibuang, yang umumnya berasal dari kegiatan yang dilakukan oleh manusia (termasuk kegiatan industri), tetapi bukan biologis (karena human waste tidak termasuk didalamnya) dan umumnya bersifat padat (Azwar, 1990).

Kelurahan Rangkapan Jaya Baru merupakan salah satu wilayah di Kecamatan Pancoran Mas Kota Depok yang terletak dibagian selatan dan merupakan pintu gerbang Provinsi Jawa Barat dengan Daerah Khusus Ibu Kota Jakarta. Kelurahan Rangkapan Jaya Baru terdiri atas 15 Rukun Warga (RW) dan 98 Rukun Tetangga (RT). Luas wilayah Kelurahan Rangkapan Jaya Baru 388,375 Km², dan terletak diketinggian 50-80 meter dari permukaan laut. Adapun batas wilayah Kelurahan Rangkapan Jaya Baru sebagai berikut: (1) sebelah utara berbatasan dengan Kelurahan Meruyung, Kecamatan Limo, (2) sebelah timur berbatasan dengan Kelurahan Rangkapan Jaya, Kecamatan Pancoran Mas, (3) sebelah barat berbatasan dengan Kelurahan Sawangan Baru, Kecamatan Sawangan, dan (4) sebelah selatan berbatasan dengan Kelurahan Cipayung, Kecamatan Cipayung. Penduduk di Kelurahan Krukut, Kecamatan Limo Kota Depok pada tahun 2017 sebanyak 39.763 jiwa yang terdiri atas laki-laki 20.219 jiwa dan perempuan 19.544 jiwa, dengan kepada penduduk sebesar $70 \mathrm{jiwa} / \mathrm{Km}^{2}$.

Sampah rumah tangga merupakan salah satu sumber sampah yang cukup besar peranannya dalam pencemaran lingkungan. Keberadaan sampah rumah tangga di suatu lingkungan memang tidak bisa dihindari. Keberadaan sampah dapat menimbulkan pencemaran tanah dan air, menimbulkan bau tidak sedap, menjadi sarang binatang yang merupakan sumber penyakit, serta mengganggu keindahan, namun demikian keberadaan sampah dapat dikurangi dan dikendalikan (diminimalkan). Upaya sederhana yang dapat dilakukan untuk meminimalkan sampah rumah tangga adalah melakukan pemilahan antara sampah organik dan sampah anorganik. Sampah organik dapat dijadikan kompos, sedangkan sampah non organik dapat dijadikan aneka kreasi (hasta karya) melalui proses daur ulang. Peran serta warga, baik bapak, remaja pria, ibu rumah tangga maupun remaja putri cukup besar dan penting artinya dalam peningkatan efisiensi pengelolaan persampahan.

Akhir-akhir ini, limbah plastik bekas botol minuman di sekitar kita semakin meningkat. Bertambahnya jumlah sampah menyebabkan dampak yang cukup buruk kepada lingkungan. Sampah dalam bentuk plastik cukup susah diuraikan. Penelitian menunjukkan bahwa sampah plastik terurai dalam jangka waktu 500 tahun.

Permasalahan sampah bukan lagi sekedar masalah kebersihan dan lingkungan saja, tetapi sudah menjadi masalah sosial yang berpotensi menimbulkan konflik. Sistem pengelolaan sampah pada dasarnya, harus dilaksanakan secara tepat dan sistemastis. Masalah sampah berkaitan erat dengan pola hidup serta budaya masyarakat itu sendiri. Oleh karena itu penanggulangan sampah bukan hanya urusan pemerintah semata, tetapi penanganannya membutuhkan partisipasi masyarakat secara luas.

Hasil evaluasi yang dilakukan Tim Pelaksana dan Mitra, diketahui bahwa kelemahan Mitra adalah (1) Keterbatasan teknologi pengolahan sampah baik sampah organik maupun sampah anorganik, (2) Alat yang digunakan untuk pengolahan sampah masih konvesional, dan belum memiliki alat pencacah sampah plastik (3) Manajemen pengelolaan sampah masih dilakukan secara konvensional, dan (4) Semua sampah di buang ke tempat pembuangan akhir (TPA), tidak ada yang dimanfaatkan. 


\section{METODE PELAKSANAAN PKM}

Sampah rumah tangga berupa bahan organik dan non-organik dapat dimanfaatkan menjadi bahan yang bernilai ekonomis. Bahan organik dapat dimanfaatkan sebagai pupuk organik dengan menggunakan teknologi pengolahan sampah (komposter). Sedangkan sampah non organik atau sampah plastik dapat menjadi produk lainnya yang bermanfaat, salah satunya dengan memperkenalkan teknologi ecobrick, sampah-sampah plastik (bekas bungkus makanan) akan tersimpan terjaga di dalam botol sehingga tidak perlu dibakar, menggunung, tertimbun dan lainlain. Teknologi ecobrick memungkinkan kita untuk tidak menjadikan plastik di salah satu industrial recycle system, dengan begitu akan menjauhi biosfer dan menghemat energi. Ecobrick menjaga bahan-bahan plastik tersebut melepaskan $\mathrm{CO} 2$ yang pada akhirnya akan menyumbang pemanasan global. Ecobrick biasanya digunakan untuk membuat furnitur modular, perabotan indoor, ruang kebun, ruang hijau, dinding struktur dan bangunan seperti sekolah dan rumah. Berdasarkan permasalahan sampah di Kelurahan Rangkapan Jaya Baru, maka solusi yang dapat ditawarkan bagi mitra dapat dilihat pada Gambar 1 .

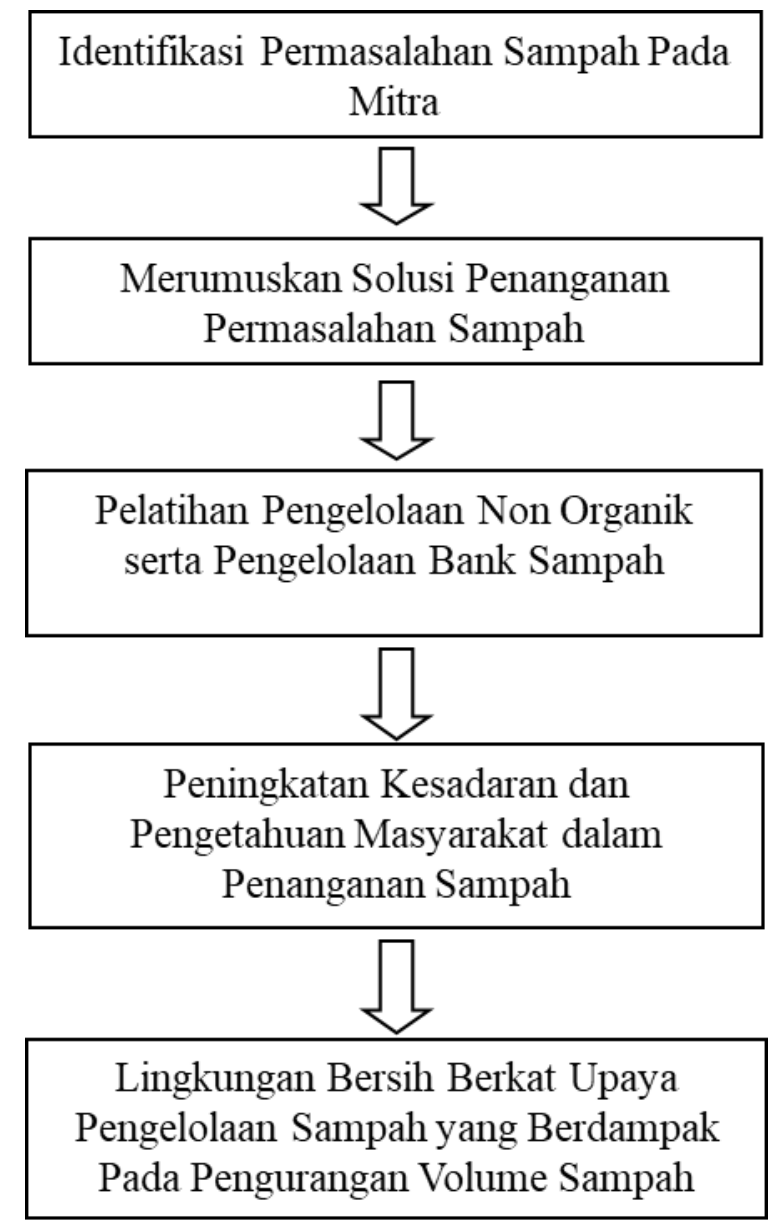

Gambar 1. Diagram Alir Kegiatan yang Ditawarkan

Kegiatan yang dilakukan adalah (1) Penyuluhan dan bimbingan tentang pengelolaan sampah non organik yang meliputi pengertian, jenis, dan model pengelolaan sampah non organik dan (2) Pelatihan pengelolaan sampah non organik (ecobricks) secara individu dan kelompok. 


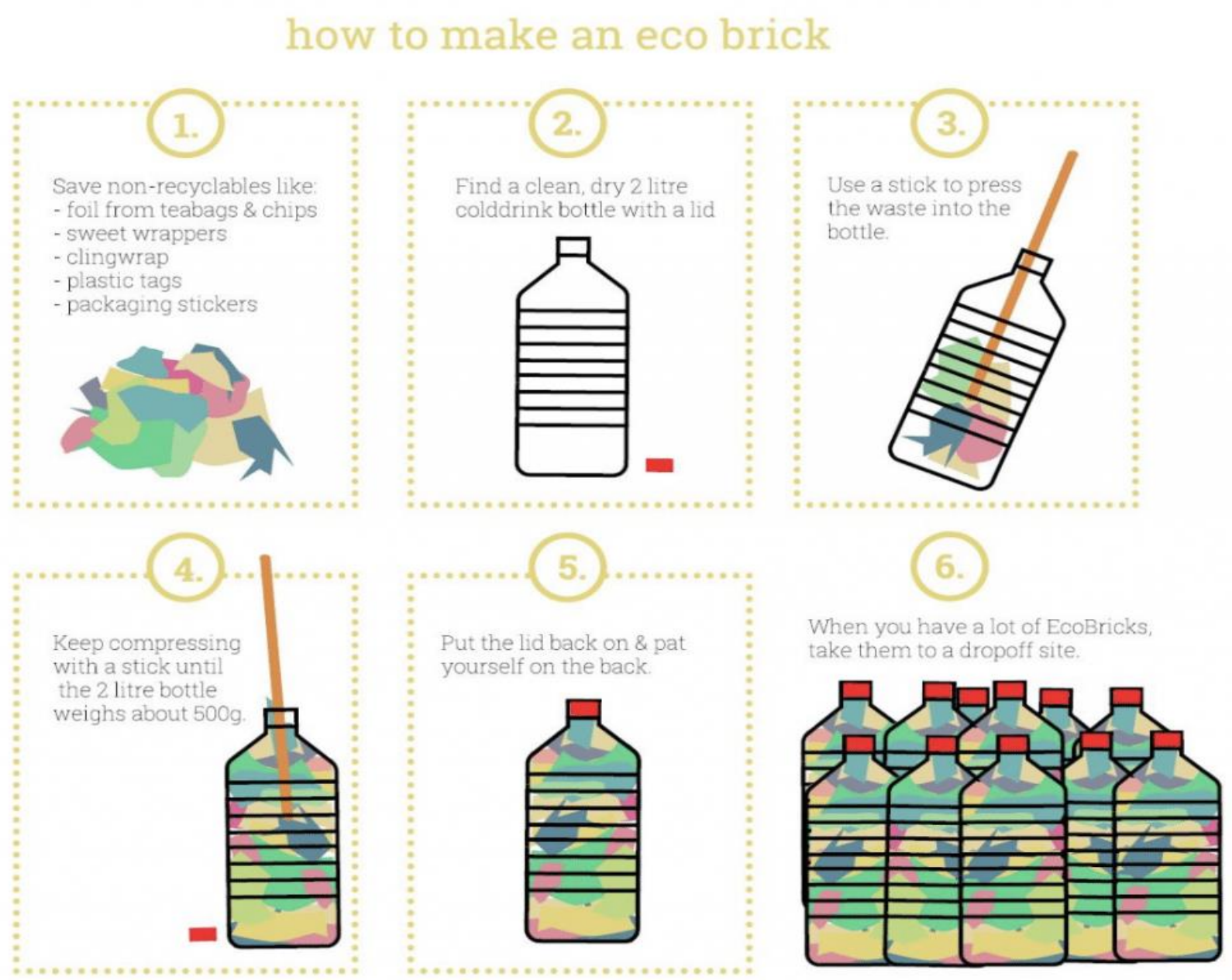

Gambar 2. Pembuatan Ecobricks

Hal-hal yang perlu diperhatikan :

1) Botol harus dalam keadaan bersih dan kering

2) Sampah plastik pun harus dalam keadaan bersih dan kering untuk menghindari bakteri tumbuh di dalam botol ecobrick

3) Putar dan tekan-tekan tongkat dan pastikan bahwa isinya padat dan merata di seluruh botol. Ini membantu memastikan bahwa botol tidak memiliki rongga dan memiliki sifat padat yang mirip dengan balok beton.

4) Untuk menguji kepadatan, kita bisa menekan botol dari luar. Ecobrick yang baik adalah saat botol tidak akan kempes dan tidak mengeluarkan bunyi ketika ditekan.

Metode yang dilakukan dalam kegiatan Program Kemitraan Masyarakat ini adalah (1) Sosialisasi Program, (2) Rencana Tindakan, pelatihan dan bimbingan serta (3) Monitoring dan Evaluasi. Metode Program Pengabdian kepada Masyarakat ini dijabarkan pada Tabel 1. 
Tabel 1 Kegiatan pengabdian kepada masyarakat

\begin{tabular}{|c|l|l|l|l|}
\hline No & \multicolumn{1}{|c|}{ Jenis Kegiatan } & $\begin{array}{c}\text { Partisipasi } \\
\text { Masyarakat }\end{array}$ & Luaran Kegiatan & \multicolumn{1}{|c|}{ Solusi Masalah } \\
\hline 1 & $\begin{array}{l}\text { Sosialisasi Program } \\
\text { Pengabdian kepada } \\
\text { Masyarakat }\end{array}$ & $\begin{array}{l}\text { Sebagai peserta } \\
\text { aktif dan me- } \\
\text { nyiapkan tem- } \\
\text { pat selama } \\
\text { kegiatan ber- } \\
\text { langsung }\end{array}$ & $\begin{array}{l}\text { Peserta memahami } \\
\text { tentang Pengolahan } \\
\text { Sampah Plastik }\end{array}$ & $\begin{array}{l}\text { Menggunakan metode } \\
\text { motivasi dan } \\
\text { melibatkan warga } \\
\text { masyarakat RW 03 } \\
\text { kelurahan Rangkapan } \\
\text { Jaya Baru. }\end{array}$ \\
\hline 2 & Rencana Tindakan & $\begin{array}{l}\text { Aktif melaku- } \\
\text { kan usaha } \\
\text { pengolahan } \\
\text { sampah non } \\
\text { organik atau } \\
\text { plastik }\end{array}$ & $\begin{array}{l}\text { Pembinaan dan } \\
\text { pelatihan kepada } \\
\text { Mitra secara detail }\end{array}$ & $\begin{array}{l}\text { Pemanfaatan limbah } \\
\text { sampah/ limbah non } \\
\text { organik dan plastik, } \\
\text { serta pendampingan } \\
\text { dalam proses } \\
\text { pengolahan sampah } \\
\text { berbasis masyarakat }\end{array}$ \\
\hline 3. & $\begin{array}{l}\text { Monitoring dan } \\
\text { Evaluasi (Monev) }\end{array}$ & $\begin{array}{l}\text { Monev bersama } \\
\text { tim pelaksana } \\
\text { PKM }\end{array}$ & $\begin{array}{l}\text { Melakukan Monev } \\
\text { hasil, dan tindaklanjut } \\
\text { usaha }\end{array}$ & $\begin{array}{l}\text { Tim pelaksana dan } \\
\text { mitra bersama-sama } \\
\text { melakukan evaluasi }\end{array}$ \\
\hline
\end{tabular}

\section{HASIL DAN PEMBAHASAN}

Pelaksanaan kegiatan Pengabdian kepada Masyarakat dengan judul: "Pengelolaan Sampah Mandiri Berbasis Masyarakat di RW 03 Kelurahan Rangkapan Jaya Baru Kecamatan Pancoran Mas Kota Depok Sebagai Upaya Peningkatan Ekonomi Masyarakat" ini diperoleh hasil yang cukup baik. Kegiatan Program Pengabdian kepada Masyarakat ini telah dilaksanakan sesuai dengan rencana jadwal yang ditetapkan dan disepakati secara bersama. Pelaksanaan kegiatan program pengabdian kepada masyarakat dilaksanakan pada bulan Juli 2019 s.d September 2019. Kegiatan pengabdian ini diawali dengan rapat koordinasi tim pelaksana, yang bertujuan merancang rencana pelaksanaan kegiatan dan sinkronisasi jadwal kegiatan, setelah itu dilakukan koordinasi dengan pihak terkait dalam hal ini perangkat RW 03 Kelurahan Rangkapan Jaya Baru, Kota Depok, diminta agar Ketua RW 03 menyiapkan tempat dan peserta sebagai sasaran program pengabdian kepada masyarakat untuk mempersiapkan hal-hal yang terkait dengan pelaksanaan program pengabdian kepada masyarakat, diperoleh kesepakatan peserta kegiatan adalah Kelompok bapak-bapak anggota pengajian RW 03 Kelurahan Rangkapan Jaya Baru, Kota Depok.

Pada tanggal 18 Juli 2019 dilaksanakan sosialisasi dan pelatihan kepada Kelompok Pengajian bapak-bapak dengan melibatkan 3 (tiga) mahasiswa Teknik Industri Fakultas Teknik UPN"Veteran" Jakarta, yang meliputi penjelasan tentang:

a. Permasalahan sampah dan ancamannya,

b. Penjelasan tentang penanganan sampah non organik : plastik, styrofoam, kaleng, bekas bungkus berbagai makanan ( kopi sachet, susu sachet, dan lain-lain)

c. Pelatihan pembuatan ecobreak.

Ecobricks adalah teknik mengolah sampah plastik menjadi sebuah benda yang bermanfaat. Kegiatan ini dapat membantu mengurangi menumpuknya sampah plastik di dunia. Caranya cukup mudah dengan cara memasukan plastik sachet ke dalam botol plastik, lalu dipadatkan hingga mengisi semua ruang botol. Standart untuk berat agar kuat untuk difungsikan sebagai berikut : 
1) untuk botol plastik $600 \mathrm{ml}$ diisi sekitar 250 gram sampah plastik atau sama dengan 2500 lembar plastik bungkus mie instan.

2) untuk botol plastik ukuran 1,5 liter diisi sekitar 600 gram atau hampir sama dengan 6000 lembar plastik bungkus mie instan.

Botol plastik hasil ecobricks yang sudah terkumpul, bisa dijual atau disusun dirangkai dan disatukan sedemikian rupa dengan bantuan perekat berupa lem kaca, yang nantinya bisa dibentuk menjadi produk furnitur sederhana seperti bangku, kursi ataupun meja, bata, tembok dan lain sebagainya. Sampah plastik yang bisa dipadatkan dan dimanfaatkan kembali tanpa harus membuang atau membakarnya.

d. Selanjutnya akan dilakukan program monitoring tentang pengelolaan sampah non organik bulan September 2019.

Dari kegiatan ini, hasil-hasil yang telah dicapai dalam kegiatan pengabdian kepada masyarakat :

partisipasi mitra terlihat (1) berperan aktif sebagai peserta dan akan mengaplikasikan dalam kehidupan sehari-hari dengan peduli terhadap sampah non organik, plastik sebagai bahan untuk dimanfaat. dan (2) membiasakan masyarakat memilah-milah sampah di rumah tangga dan mengolah/mendaur ulang sampah yang dihasilkan, (3) bertambahnya pendapatan masyarakat yang mengelola sampah plastik atau non organik menjadi produk lainnya yang bermanfaat, (4) berkurangnya timbulan volume sampah harian, terutama dari sumber rumah tangga (domestik), tidak semua di buang ke tempat pembuangan akhir (TPA), dan (5) terciptanya kondisi lingkungan yang bersih, sehat dan teratur. Hasil-hasil yang telah dicapai dalam kegiatan pengabdian kepada masyarakat dapat dilihat pada Tabel 2.

Tabel 2. Hasil-hasil yang telah dicapai dalam kegiatan pengabdian kepada masyarakat

\begin{tabular}{|c|l|l|}
\hline No & \multicolumn{1}{|c|}{ Rencana } & \multicolumn{1}{|c|}{ Hasil / Realisasi } \\
\hline 1. & $\begin{array}{l}\text { Sosialisasi Program Pengabdian } \\
\text { kepada Masyarakat }\end{array}$ & $\begin{array}{l}\text { Peserta memahami tentang } \\
\text { Pengolahan Sampah Plastik }\end{array}$ \\
\hline 2. & Rencana Tindakan & $\begin{array}{l}\text { berperan aktif sebagai peserta dan } \\
\text { akan mengaplikasikan dalam } \\
\text { kehidupan sehari-hari dengan peduli } \\
\text { terhadap limbah sampah/ limbah non } \\
\text { organik dan teknik pemilahan plastik, } \\
\end{array}$ \\
& $\begin{array}{l}\text { serta pendampingan dalam proses } \\
\text { pengolahan sampah berbasis } \\
\text { masyarakat }\end{array}$ \\
\hline 3. & Monitoring dan Evaluasi (Monev) & \\
\hline
\end{tabular}

\section{KESIMPULAN DAN SARAN}

Dalam Pelaksanaan kegiatan Pengabdian kepada Masyarakat dengan judul: "Pengelolaan Sampah Mandiri Berbasis Masyarakat di RW 03 Kelurahan Rangkapan Jaya Baru Kecamatan Pancoran Mas Kota Depok Sebagai Upaya Peningkatan Ekonomi Masyarakat" ini diperoleh hasil yang cukup baik, terlihat kelompok bapak-bapak pengajian sangat antusias serta berperan aktif sebagai peserta dengan penyiapan alat dan bahan serta praktek langsung pembuatan Ecobricks. Peserta mengaplikasikan dalam kehidupan sehari-hari dengan mengumpulkan sampah plastik untuk dilakukan pemilahan dan dilakukan pengolah sampah plastik untuk bisa dijual sehingga dapat menambah pendapatan masyarakat. 


\section{REFERENCES}

Azwar, Azrul. 1990. Pengantar Ilmu Kesehatan Lingkungan, Yayasan Mutiara, Jakarta.

Basriyanta. 2007. Memanen Sampah. Yogyakarta. Kanisius

Budi, Hieronymus Santoso. 1998. Pupuk Kompos. Yogyakarta. Kanisius

Dwiyanto. BM, 2011, Metode Peningkatan Partisipasi Masyarakat dan Penguatan Sinergi dan Pengelolaan Sampah Perkotaan. Jurnal Ekonomi Pembangunan, Vol 12, No. 2, Desember 2011

George, Hillary dan Samuel, 1999. Integrated Solid Waste Management Engineering Principles and Management Issues.

Hadiyanto dkk, 2011. Pengelolaan Sampah Rumah Tangga di Kecamatan Daha Selatan. Jurnal Ilmu Lingkungan Vol. 9. No. 1. April 2011

Kusnawati, dkk, 2012. Pemberdayaan Masyarakat Pengelolaan Sampah di Dusun Mrican Sleman. Jurnal Health and Sport. Vol. 5. No. 3. Agustus 2012

Sejati, K. 2009. Pengolahan Sampah Terpadu Dengan Sistem Node, Sub Point, dan Center Point. Penerbit Kanisius, Yogyakarta. 